\title{
Account-Making: A Model for Understanding and Resolving Distressful Reactions to Retirement from Sport
}

\author{
J. Robert Grove, David Lavallee, and Sandy Gordon \\ The University of Western Australia
}

\author{
John H. Harvey \\ The University of Iowa
}

In this paper, we examine the account-making model of Harvey, Weber, and Orbuch (1990) as a framework for understanding negative reactions to retirement from competitive sport. Theoretical aspects of the model are first summarized, and a case study is then presented to illustrate the central role of account-making in the adjustment process for an Olympic gold medallist. We conclude by suggesting ways that sport psychology consultants can facilitate account-making and thereby help athletes to cope with distressful reactions to retirement.

As the demands associated with competitive sport have increased over time, so has academic interest in career transition issues among athletes. A growing body of empirical and theoretical research has emerged during the past 30 years that brings attention to the factors involved in the process of disengaging from elite-level sport (Ogilvie \& Taylor, 1993). A number of these studies have examined the overall phenomenon and identified that reasons for career termination, developmental experiences of the athlete, and available resources at the time of retirement can all have a significant impact on the quality of adjustment to career termination (e.g., Gordon, 1995; Taylor \& Ogilvie, 1994). Research on the career transition process has also offered a variety of perspectives on how to assist athletes in preparing for the inevitable end of their career (e.g., Baillie \& Danish, 1992; Sinclair \& Orlick, 1993).

J. Robert Grove and Sandy Gordon are in the Department of Human Movement at the University of Western Australia, Nedlands, Perth, Western Australia 6907, Australia. David Lavallee is now at the School of Leisure and Sport Studies at Leeds Metropolitan University, Leeds LS6 3QS, England. John H. Harvey is with the Department of Psychology at the University of Iowa in Iowa City, IA 52242. 
A number of studies have also focused on the adjustment difficulties experienced by retiring athletes. Although the adjustment process does not appear to be problematic for all athletes (Coakley, 1983; Curtis \& Ennis, 1988; Greendorfer \& Blinde, 1985), there is evidence that some sport performers do indeed experience serious adjustment crises when faced with retirement (e.g., Allison \& Meyer, 1988; Kleiber \& Brock, 1992; Messner, 1992; Werthner \& Orlick, 1986). As a result, a variety of explanatory models have been employed by sport scientists in an effort to gain a better understanding of the athletic career termination process. For example, social gerontological theories of aging have been applied to sport in order to equate the process of athletic retirement with retiring from the workforce (e.g., Johns, Linder, \& Wolko, 1990). Thanatological models, in a similar fashion, have utilized theories of death and dying to explain distressful reactions to athletic retirement (e.g., Blinde \& Stratta, 1992). Both of these perspectives have been criticized, however, because they tend to view retirement as a singular event and more or less ignore the possibility of identity development outside of sport. Transition models have been proposed as an alternative framework for research in this area (e.g., Swain, 1991), but these models have also been criticized for failing to offer a holistic view of the career termination process. As Taylor and Ogilvie (1994, p. 4) have stated, "The theoretical models that have been applied to retirement from sport do not indicate what factors lead to the traumatic responses or what enables individuals to progress through the respective stages to reach closure."

With these criticisms in mind, a number of theorists have proposed more comprehensive conceptual models of retirement from sport (e.g., Gordon, 1995; Sinclair \& Orlick, 1993; Taylor \& Ogilvie, 1994). These domain-specific models, which examine the entire course of athletic retirement, include the following components: (a) causal factors that initiate the career termination process, (b) developmental factors related to retirement adaptation, (c) coping resources that affect the responses to retirement, (d) quality of the adaptation to retirement, and (e) treatment issues for distressful reactions to retirement. As Taylor and Ogilvie (1994) have stated, the strength of these conceptual models is that once specific retirement difficulties are demonstrated, appropriate therapeutic interventions can be recommended. At the present time, however, there has been very little research conducted on the identification of athletes who experience severe difficulties upon retirement from sport, and no systematic investigations on specific intervention techniques for those individuals.

A close inspection of the career transition literature indicates that at least 11 studies have specifically examined and documented distressful reactions to retirement from sport (Allison \& Meyer, 1988; Blinde \& Stratta, 1992; Curtis \& Ennis, 1988; Greendorfer \& Blinde, 1985; Lavallee, Gordon, \& Grove, 1997; McInnally, Cavin-Stice, \& Knoth, 1992; Parker, 1994; Sinclair \& Orlick, 1993; Svoboda \& Vanek, 1982; Werthner \& Orlick, 1986; Wylleman, De Knop, Menkehorst, Theeboom, \& Annerel, 1993). The athletes in these 11 studies $(N=2116)$ represented a wide range of sports and ability levels. As demonstrated in Table 1, a synthesis of the findings reveals that more than 19 percent $(n=410)$ of these athletes experienced considerable emotional disturbance in relation to their retirement from sport. We, therefore, believe that further attention should be given to the development of therapeutic interventions for distressful reactions to retirement from sport, and we summarize here an intervention model that views accountmaking as a central therapeutic principle. 
Table 1 Summary of Studies Measuring Distressful Reactions to Retirement from Sport

\begin{tabular}{|c|c|c|c|c|c|}
\hline \multirow[b]{2}{*}{ Investigation } & \multicolumn{2}{|c|}{ Sample } & \multicolumn{3}{|r|}{ Number and type of distressful reactions } \\
\hline & $N$ & Level & $n$ & Percentage & Description \\
\hline Svoboda \& Vanek (1982) & 163 & Olympic & 29 & 17.7 & Had yet to recover psychologically (p. 171) \\
\hline Greendorfer \& Blinde (1985) & 1124 & Collegiate & 191 & 17.0 & Indicated some/extreme dissatisfaction with self (p. 107) \\
\hline Werthner \& Orlick (1986) & 28 & Olympic & 9 & 32.1 & Had a very difficult time in the transition (p. 344) \\
\hline Allison \& Meyer (1988) & 20 & Professional & 6 & 30.0 & Had feelings of isolation and loss of identity (p. 218) \\
\hline Curtis \& Ennis (1988) & 96 & Amateur & 14 & 14.6 & Experienced quite a feeling of loss (p. 95) \\
\hline Blinde \& Stratta (1991) & 20 & Collegiate & 16 & 80.0 & Indicated the feelings often parallelled death and dying (p. 8) \\
\hline McInally et al. (1992) & 367 & Professional & 96 & 26.2 & Experienced moderate to severe emotional adjustment (p. 4) \\
\hline Sinclair \& Orlick (1993) & 199 & Amateur & 22 & 11.1 & Felt generally dissatisfied about life (p. 143) \\
\hline Wylleman et al. (1993) & 44 & Olympic & 3 & 6.8 & Were confronted with severe emotional problems (p. 904) \\
\hline Parker (1994) & 7 & Collegiate & 6 & 85.7 & Reflected negative expressions and experiences (p. 299) \\
\hline Lavallee et al. (1997) & 48 & Amateur & 18 & 37.5 & Experienced highly distressful reactions to retirement (p. 7) \\
\hline Total & 2116 & & 410 & 19.4 & \\
\hline
\end{tabular}




\section{Account-Making and Coping with Distressful Reactions to Retirement}

Harvey, Weber, and Orbuch (1990) adapted Horowitz's (1986) model of coping with loss to produce a general framework for understanding how people cope with extremely stressful experiences. Whereas Horowitz emphasizes the role of working-through in recovery, Harvey and colleagues propose that a central component of the working-through process is the construction of a story about the traumatic event (i.e., its nature, why it happened, how one feels about it, and what it means for the future). This account, which represents the person's understanding of their situation at a particular point in time, is then refined and elaborated as he or she gains perspective on their plight. An important mechanism by which refinement takes place is confiding activity, wherein portions of the account are revealed to close others. If these confidants react to the account in a helpful manner (i.e., with empathy, compassion, understanding, and timely feedback), then the individual is encouraged to acknowledge the stressor and deal with it rationally and constructively. If the confidants do not react in a helpful manner (e.g., by denying the pain, being judgmental, and/or not offering feedback), then the individual is much less likely to acknowledge the reality of the situation, and psychological distress will persist and grow (Harvey, Orbuch, Chwalisz, \& Garwood, 1991).

This conception of account-making as an essential adjustment mechanism can be readily applied to coping with retirement from elite-level sport. When an athlete retires, there may be a number of negative psychological consequences associated with the termination of the sport career. For example, there may be a loss of material and symbolic rewards derived from participation, and the athlete will therefore need to find new ways to earn a living and contribute to society. The athlete will also need to develop new interests toward which he or she can direct the considerable time and energy that were previously devoted to training. At another level, adjustments in self-image will probably be necessary because daily activities will be less visible and perhaps less publicly esteemed. Feelings of absorption, joy, and accomplishment, which may have stemmed primarily from an intense and successful involvement in high-level competitive sport, will now need to be achieved by meaningful involvement in other endeavors. A social environment that previously involved close camaraderie with teammates is likely to be disrupted, and alternative sources of social interaction and support will need to be found.

These experiences will be matters of construal for the retired athlete, and individual differences will exist in how well prepared they are to deal with the interpretative task. As shown in Figure 1, however, Harvey, Weber, and Orbuch (1990) argue that people typically react to traumatic stress in a series of steps that may be linear or may involve back and forth movement over time. In the early stages of a distressful reaction, the retired athlete is likely to feel shocked or overwhelmed, exhibit signs of panic, and/or cry out for help. This outcry phase may include a sense of despair or hopelessness, and, in severe cases, the athlete's very survival may be at risk. Next, during a period of simply "getting by a day-at-atime," the athlete is likely to employ denial, withdrawal, fantasy, and obsessive rumination as coping mechanisms. It is at this point that rudimentary accountmaking activity often begins.

A working-through phase follows, which is characterized by intensified account-making activities where the reality of the transition is repeatedly confronted, 


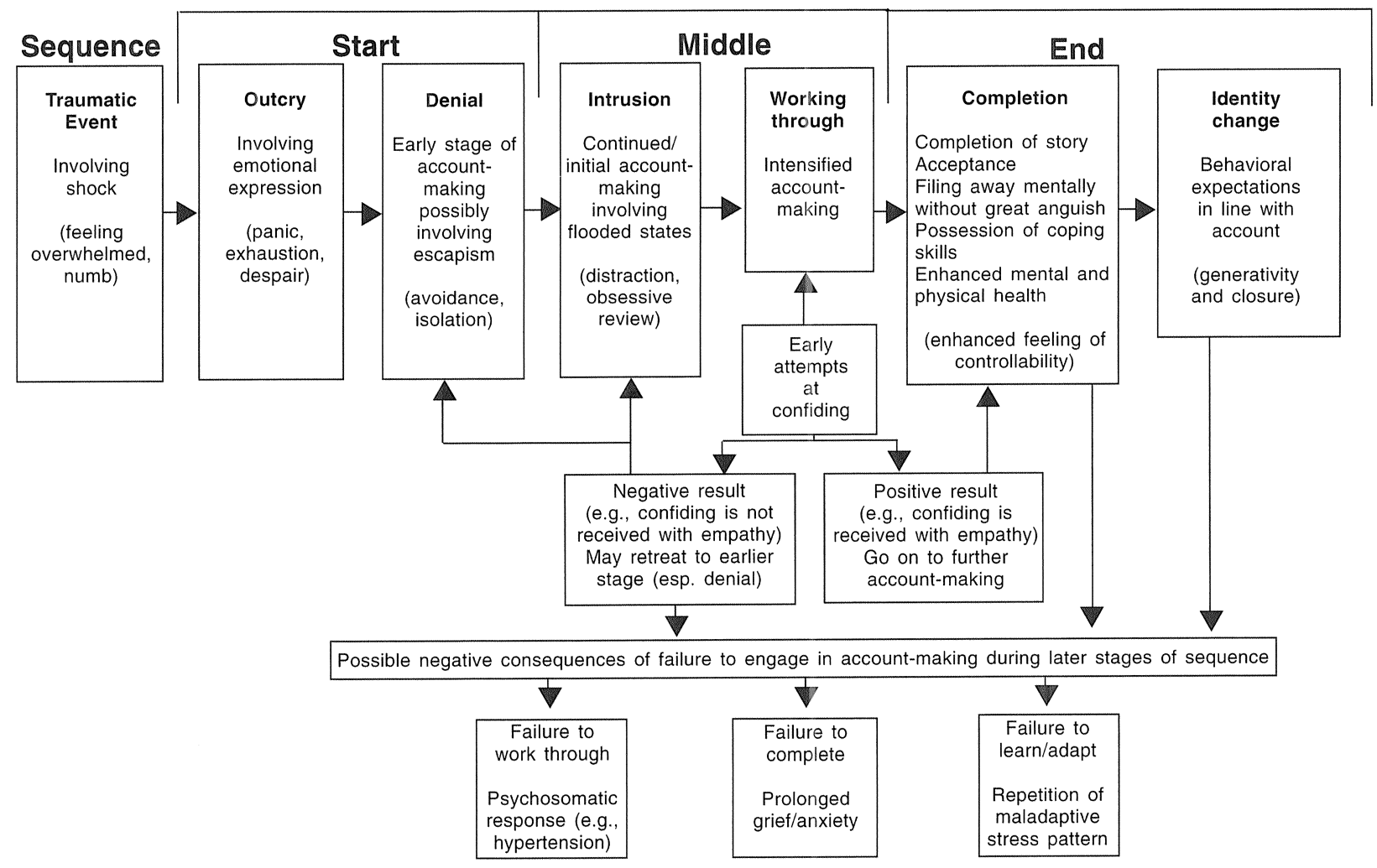

Figure 1 - The account-making model. From Interpersonal Accounts: A Social Psychological Perspective, by J.H. Harvey, A.L. Weber, and T.L. Orbuch, 1990, Oxford: Blackwell. 
put aside, and then revisited. Over time, these activities produce a personal and elaborated story of the experience that includes descriptions, attributions, characters, plots, memories, emotional expressions, behavioral expectations, and future plans. This elaborated account assists in attaining closure and becomes the basis for a new identity that allows the athlete to make use of unique experiences, interests, and skills in constructive ways. Ultimately, the new identity may include an active concern for the welfare and guidance of others who are faced with similar circumstances (generativity; Erikson, 1963). Although there is some debate about the relative merits of different forms of account-making in achieving such results (e.g., Pennebaker, 1990), Harvey and colleagues argue that confiding activity (i.e., reciprocal, account-focused interaction with close, empathetic others) is a crucial element of successful working-through, completion, and identity change.

\section{An Illustrative Case Study}

The structural and functional utility of the account-making model is dramatically illustrated by the case of Shane Gould Innes. Shane was born in Sydney, Australia, on October 25, 1956 (the day competition began at the 1956 Melbourne Olympics). At the age of 15, she won three gold, one silver, and one bronze medal at the 1972 Munich Olympics and became the only woman in history to simultaneously hold world records in every recognized freestyle swimming event $(100 \mathrm{~m}, 200 \mathrm{~m}$, $400 \mathrm{~m}, 800 \mathrm{~m}$, and $1500 \mathrm{~m})$. Less than a year later, Shane announced her retirement from competitive swimming.

We were initially interested in Shane's "retirement story" because of her historic achievements in sport and her publicly acknowledged difficulties in adjusting to an early and permanent retirement from international competition. We therefore analyzed material written by her and about her (Burke, 1990; Davis, 1993; Fitzsimons, 1990; Gordon, 1994; Gould, 1972; Guilliatt \& Dwyer, 1995; Hemery, 1986; Howell \& Howell, 1988; Innes, 1992; Lester, 1984; Phillips, 1992; Writer, 1990), and we invited her to participate in a structured interview about her retirement experiences. In the process of analyzing this information, it became clear that the natural history of Shane's adjustment to retirement over the past 25 years was strikingly similar to the stages and processes shown in Figure 1. We illustrate those similarities here using components of Harvey, Weber, and Orbuch's (1990) account-making model as an organizational framework. ${ }^{1}$

\section{Traumatic Event and Outcry}

Shane retired from competitive swimming in 1973 at the age of 16 . Prior to her success at the 1972 Munich Olympics, she had been competing in state-level competitions for 7 years, national competitions for 5 years, and international competitions for 3 years. In that time, she had won 14 Australian swimming titles and set 11 world records. Her decision to terminate her athletic career was a complex and difficult one that was influenced by a variety of factors:

${ }^{1}$ Source-checking procedures were used to enhance the validity of our interpretations (Lincoln \& Guba, 1985; Patton, 1990). Shane provided feedback on both the interview transcript and a draft of this manuscript. All quotations presented here are from the interview unless otherwise noted, and they are used with Shane's permission. 
After the Olympics in 1972, I had difficulty focusing on new goals and felt as if a bubble had been deflated. You know, all the hype and build-up to the Olympics, and I hadn't really focused beyond that, although I knew the world swimming championships were coming after in September 1973, and I had those in sight. ... There were some arguments going on with my father and my coach . . . and I think that there was just a lot of tension there because my parents had felt that they had lost me to the world. ... So my dad organized for me to go and stay in America because I was losing interest in swimming and having trouble focusing. I could not do an effort swim in training at that time, and I was flat and not excited about swimming. I did not have the motivation I had before the Olympics. . . I gradually did less and less training and put on a lot of weight, and when I came back my parents said ... "Quit swimming if you want, it doesn't matter. Go to school or whatever ... just try to get a perspective on things." So I decided to pull out and go and get my life together. That was a very difficult time, back then in 1973. I would never want to live 1973 again.

It has been suggested that the quality of adjustment to athletic retirement is mediated by the reason(s) for career termination (Gordon, 1995; Taylor \& Ogilvie, 1994). In Shane's case, her decision to retire appears to have been related to a postOlympic loss of motivation in combination with identity conflicts she was experiencing at that time of her life. Such identity conflicts often arise when adolescents are trying to come to grips with their future (Erikson, 1963), but they may have been magnified by Shane's notoriety. Following her sporting success at the Olympics in 1972, she was named Australian of the Year, and, as Phillips (1992) has noted, she was quickly transformed from a well-known schoolgirl swimmer into a national idol. Despite these achievements, however, things seemed superficial, and she felt there must be more to life than being a successful athlete. She described the specific adjustment difficulties she experienced as follows:

I was pretty vulnerable in 1973 to 1975 and had a very difficult time adjusting. . . . I didn't talk much about my retirement experiences. . . It was like I was running away from it at first [italics added]. I was very angry, and I know I was placing the blame on other people a lot. Initially, I was angry with people for not protecting me and not telling me what was going to happen. ... It was very difficult; I felt like I had an obligation to the public to keep performing, [but] at the same time, I was thinking that I really do not want to do this any more. Personally, I was asking myself "what else could I do," while other people were asking how much faster I could swim. I think it is this tension that has stayed with me all these years.

\section{Denial and Intrusion}

In the first few years following her retirement, Shane gradually withdrew from the world of competitive sport. The Australian public had hoped she would come out of retirement, but to her, "It was like I had been to the top of the mountain and found nothing there, so why go back?" (Phillips, 1992, p. 100). She finished her final year of high school in 1975 and was married in the same year. As suggested in the following quotation, she appeared to isolate herself in an effort to cope: 
The circles I hung in had young people who probably had little or no interest in sport. ... Most of the time, I was with my husband alone. We'd go to the beaches alone and hang out with small groups of people. ... I didn't talk much about my swimming experiences [italics added] .. . I was just soaking up new knowledge and understanding society and people.... I occasionally went to swimming events, but my husband was not interested in competitive sport, so he didn't accompany me. ... I just dropped out and people tiptoed around me seeing that I wanted to drop out and quit.

With regard to account-making activity, it appears that Shane avoided discussion of career transition issues in the years immediately following her retirement. Part of the reason for this seems to be that she did not fully understand what she was experiencing and, thus, had difficulty explaining it to others. As Harvey and colleagues (1991) have suggested, however, account-making typically begins in private reflection, and it may take quite some time before the individual feels ready to engage in confiding activity. Thus, it is likely that Shane did engage in rudimentary forms of account-making at this time (e.g., thinking about the experience or relating selected parts of her account to family and friends). Indeed, she admitted to having little difficulty in discussing her swimming achievements at that point but, at the same time, having great difficulty in dealing with the emotional consequences of her retirement:

I began to feel that there was not much significance in my swimming career and my life, and I didn't deal with it. I hadn't confronted it [italics added], although. ... I was very open about my swimming achievements. . . But I couldn't bring the two together, outside of when I taught swimming. When we moved to Margaret River, in my little community I had a private swimming school for three years. ... So that was a way I could be Shane Gould the swimmer and my community would recognise that. And each Olympic year I went to the schools on invitation and talked about the Olympics. I was quite free and open with the community, but it became increasingly difficult because ... I felt I was living as two people. That was one way of protecting myself. I was making a new life on the one hand and paying homage to this other life, this other person, at the same time.... If I accepted an invitation to go to an Olympic funding thing or be honored for the Swimming Hall of Fame ... or go and do a television interview, it became a tug-of-war because all my husband saw was me when I came back. And when I came back, I was emotionally a mess. It was like I was in a depression [italics added]. . . . Even three days later, I would be thinking about my swimming days and feel morose. I found even if I looked at photographs and letters I got very reflective, and that hung with me for quite a number of years [italics added].

\section{Working-Through}

As shown in Figure 1, the early stages of adjustment to traumatic stress are often characterized by denial as well as intrusive thoughts, images, and memories. Such reactions are quite natural, and they are adaptive because they provide relief from the stress and give impetus to initial account-making activity. However, they can become maladaptive if they persist for too long. More specifically, significant movement toward recovery requires that individuals move beyond denial/intrusion 
and be willing/able to elaborate their account, openly confide in significant others, and thereby "work-through" the painful emotions associated with their experience (Harvey, Weber, \& Orbuch, 1990). For Shane, this did not happen until 1990 (17 years after she had retired from competitive sport). At that point, she and her family acknowledged recurrent patterns in her behavior, and she sought professional advice. She was subsequently referred to a sport psychologist who discussed her personal retirement experiences with her and provided her with general information on career transitions as well as specific information on retirement from sport. As indicated below, these interactions helped Shane to confront some of the emotions associated with her retirement and gave her a greater sense of control over her situation:

I was confused and bewildered by my range of emotions in relation to my career and its ending (Innes, 1992, p. 6). Things didn't change for me until I recognised that there was this pattern, and that there were some things that were not resolved, and that what was going on inside of me was bigger than usual. I didn't think there were any known answers for what I was going through. ... [A sport psychologist] gave me some literature on sports retirement, stress, and career transitions, and my initial reaction was "why didn't anyone tell me this." . . . I saw that other athletes had the same experience, and that was a huge relief that I was not on my own. There was a name for what I was feeling, and there were other people feeling the same, so I just felt like one of the crew and not on my own. I remember the scene. I was standing at the end of my bed. I had been lying in bed reading the literature, and in the morning I read a bit more of it, and I was different because it gave me an understanding of it.

The gathering of information has been identified as an important coping strategy in the social psychology literature (e.g., Carver, Scheier, \& Weintraub, 1989; Lazarus \& Folkman, 1984), and the provision of carefully chosen reading materials can be a useful therapeutic tool (Riordan \& Wilson, 1989). For Shane, obtaining information about the career transition process and the reactions of other athletes was an important step toward recovery, because it validated her emotions and stimulated confiding activity:

I discussed things with my mother and with my husband. . . My visits with my mother were brief, and I was not seeing her every day. It was just chatting on the phone for five minutes, and so I'd just drop all this information on her. Until she heard more of what I was saying, she did not understand. But I did discuss it with my family, mostly with my husband. . . I often had the chance to speak publicly, with a snippet here and there. . . There were just isolated events with people not necessarily related. It was just talking about it and validating it and explaining it. This helped me to understand it and the dynamics that were going on.

There was one guy who has been a really good mate for me. He was an Australian swimmer and won gold medals ... and he was very supportive of me. . . . His immediate reaction was "I understand what you are saying, Shane, and I am really sad that it happened for you." So that was all I needed to know; that it was alright to feel like this, and that it is a real thing. . . He 
validated it for me. That was the most important thing. And it was not like he had to do something about it. It was just that he was there and recognized it. He was not trying to offer any quick-fix solutions. It was just "I hear what you are saying." I think it is very valuable that someone can hear what you are saying.

As outlined in Figure 1, positive confiding experiences play an important role in recovery by providing feedback that assists in the development of a more refined, elaborate, and complete account. Lavallee et al. (1997) have obtained evidence along these lines with specific reference to retired athletes. At the same time, there is also evidence that negative confiding experiences can discourage further attempts at openness and stimulate a relapse to the use of less adaptive coping processes such as denial, avoidance, and rumination (Harvey et al., 1991; Pennebaker, 1990). Although Shane encountered both helpful and nonhelpful responses to her attempts at confiding, she was able to distinguish between them and thereby continue her movement toward completion:

Some of the reactions were "but you have had such great experiences. ... You're selfish; you are feeling sorry for yourself; it has all been good for you." Some of it was "I don't understand, and I really don't want to know." And I began to understand that those were not the people to talk to. I needed to talk to people who understood and could validate what I was saying and feeling.

\section{Completion and Identity Change}

The cognitive-emotional effort of the working-through phase leads to an increased sense of control over retirement-related thoughts and feelings. It also produces a willingness to feel the pain of the situation and a sense of having gained valuable coping skills (Harvey, Weber, \& Orbuch, 1990). However, it is still important for the athletes to "complete" their account and, by doing so, come to accept their personal transition experiences as an integrated part of who they were, who they are, and who they will become. Failure to do so can result in prolonged grief, repetition of maladaptive behavior patterns, and/or psychosomatic reactions. Successful completion, on the other hand, enables the individual to "file away" the event, achieve a sense of closure, and plan for a meaningful future.

The penultimate step in this process of completion and identity change is generativity (i.e., an active concern for the welfare of others). In Shane's case, the account-making process was central to her search for meaning and the eventual development of generativity. In her own words, "It [account-making] has helped me to not feel alone, and it has caused me to feel like I have something meaningful and significant to contribute to the swimming arena apart from being just a name." Once she began to sense closure in her "retirement story," she also developed a desire to share what she had learned with others. In this way, account-making became an end in itself for Shane:

I thought other people needed to know about this, so that is when I started talking. . . . I reread all the literature and worked out strategies and tried to start talking, but it was bigger that I thought it would be. It was too huge for one person to deal with, so I tried to pinpoint key people like the Confederation 
of Australian Sport, the Australian Olympic Committee, and [I] took every opportunity to speak to the media. . . . I explored a lot of areas just to have the whole idea become common knowledge. . . . I thought . . . a strategy could be made to help people understand the dynamics of the sporting career. So that was my strategy on how to deal with it myself, and also I suppose it was a significant thing to do [italics added].

Since 1990, Shane has become a highly visible spokesperson for career transition issues in Australian sport. In the last few years, she estimates that she has given 15 to 20 interviews focusing specifically on her own adjustment to retirement. "Whenever someone asks me about it from the media, I will speak just to make sure it is still being talked about. . . I'd like to see the issues of detraining and retirement stress become as familiar as sports injury prevention and eating pasta as a pre-competition food" (Innes, 1992, p. 6). Although some people may never achieve a feeling of closure after experiencing a major trauma in their lives, everyone has the capacity to transform their pain and despair so that it contributes to the quality of their own lives and the lives of others (Harvey, 1996; Harvey, Orbuch, Weber, Merbach, \& Alt, 1992). For Shane Gould Innes, the development of an elaborated personal retirement account and the sharing of her story with others have been essential elements of the movement toward closure:

So the solution for me was, first of all, being able to give it a name and talking about it to others; not denying it any more, embracing it, and realizing that my sporting life had changed my life forever, and I could not go back to not having been an athlete. So by doing that, there was a little bit of a sense of loss of not ever being able to be normal again, but also looking at it as a great privilege and a great gift. In 1990 I said I am not going to run away from this lying in my life any more. I'll turn around and embrace it, and this lie has now become my friend. So that is what I am doing. I am not running away from it any more. I am making it work for me and accepting it and using it to enhance my own life and contribute to society.

\section{Implications for Practice}

Helping athletes to make a successful transition to post-athletic careers is an important responsibility of the sport psychology practitioner (Murphy, 1995; Petitpas, Champagne, Chartrand, Danish, \& Murphy, 1997). It is therefore surprising that potential strategies for facilitating this transition have not, for the most part, been delineated or investigated in detail. We believe that increased attention should be directed toward methods for helping athletes to work through the emotional distress that sometimes accompanies retirement from competitive sport, and we propose that Harvey, Weber, and Orbuch's (1990) account-making model offers much promise in this regard. Their model has been proposed as an appropriate intervention framework for a variety of stressful experiences, and retirement, in particular, is an area where the model could have useful applications (Harvey, Orbuch, \& Weber, 1990). Shane Gould's account of her retirement experience suggests that this model certainly has relevance for understanding the natural history of career transition among sport performers. At the same time, the protracted nature of her transition highlights the need for practitioners to facilitate the account-making 
process and thereby enable athletes to move efficiently toward completion and identity change.

The construction of narrative accounts is a natural tendency that serves basic needs for explanation, meaning, and control (Baumeister, 1991). Moreover, the motivation to construct such accounts is especially strong when the individual is confronted with unexpected, negative, or highly stressful events, because the process of account-making assists in both stress appraisal and adaptive coping (Harvey, Orbuch, \& Weber, 1990; Weber \& Harvey, 1994). Practitioners can therefore expect athletes who are dealing with recent or imminent retirement to engage in spontaneous account-making about the precursors to their decision, their feelings about it, and the possible consequences of the change for themselves and others. Such spontaneous account-making is likely to begin in the denial phase, intensify during the working-through phase, and mature during the completion phase (Figure 1; Weber \& Harvey, 1994). Initial story lines may be fragmented, selective, and/or distorted, and the athlete may be hesitant to share them. Nevertheless, these rudimentary accounts will represent what he or she believes to be relevant at that point in time (Heatherton \& Nichols, 1994).

An important initial task for the sport psychology practitioner is therefore to create an atmosphere where the athlete is willing to openly reflect on the current version of the retirement story and begin to refine it . In other words, a climate of meaningful involvement and trust must be established so that support, validation of feelings, and assistance can be offered (Billings, 1994). At first, this might involve suggesting constructive activities, sharing information about oneself, offering companionship, asking the athlete to teach you or others how to do something, and/or providing information about life transitions and the retirement experiences of other athletes (Riordan \& Wilson, 1989; Weber \& Harvey, 1994). Later, it might involve "breaking the silence" by asking both open-ended and specific questions about various phases of the athlete's career (including the latter stages when retirement issues may have first become salient), tactfully confronting persistent denial, encouraging self-exploration of roles, values, interests and skills (Petitpas et al., 1997), and/or recognizing client-initiated tests of trust. Such tests include revealing secrets, deprecating oneself, requesting favors, inconveniencing the counselor, and questioning the counselor's dedication (Fong \& Cox, 1989).

At the same time, it is important to realize that neither confiding nor account-making can be rushed. Both processes will involve periods of resistance, progress, plateau, and reversal. Athletes will also differ in their ability to understand their own experiences, express themselves, engage in personal disclosure, and construct articulate accounts. For this reason, initial attempts at confiding and account-making may best be done in writing so that the athlete is better able to organize and clarify his or her thoughts and feelings (Pennebaker, 1990; Weber \& Harvey, 1994). A wide variety of therapeutic writing techniques could be used, and these include diaries, journals, poems, letters, stories, and autobiographies (Riordan, 1996). Such activities can be approached from a number of traditional behavior-change perspectives (Meichenbaum \& Fitzpatrick, 1993; Wolff \& Lester, 1989), and various degrees of structure can also be imposed to suit the athlete's preferences, abilities, and readiness to deal with specific issues.

Regardless of the specific format(s) and degree of structure, however, it is important to encourage progressive movement toward more "complete" accounts that include explanations, memories, and emotional reactions to the athlete's prior 
sport involvement, transition experiences, and uncertain future (Spera, Buhrfeind, \& Pennebaker, 1994). At the same time, it is important to encourage the establishment of new behavioral patterns (e.g., involvement in the teaching of young athletes) because of the potent influence of one's behavior on self-perception and identity (Bem, 1972). These elaborated accounts and new behavioral involvements can then form the basis for private reflection, discussions with significant others, support group interactions, and/or private consultation with the sport psychologist.

In the short term, feedback from these activities will enable the athlete to work through loss-related issues such as denial or feelings of despair, further refine a personal retirement story, and develop plans for future behavior. Over time, the complementary processes of account-making, confiding, refining the account, and engaging in new behavior patterns will accomplish a number of important therapeutic goals. More specifically, the retirement experience will be chronicled and its reality will be confirmed; personal memories and emotions will be formally recorded as an important part of the experience; the athlete will actively practice communication and interpersonal skills; the athlete will achieve a sense of integration, closure, and identity change; and the athlete will be prepared to embrace new and different challenges (cf. Leick \& Davidsen-Nielsen, 1991; Weber \& Harvey, 1994).

As noted in Figure 1, a desirable correlate of completion and identity change is generativity (i.e., an active concern for the welfare of others). We believe sport psychology practitioners can facilitate generativity by consciously encouraging retired athletes to discuss their refined accounts with athletes who are in the midst of their careers. Such an approach has been used successfully within comprehensive drug education programs (Tricker, Cook, \& McGuire, 1989), and it could also be incorporated into career mentoring programs for athletes (Jackson, Mayocchi, \& Dover, 1997; Perna, Zaichkowsky, \& Bocknek, 1996). By doing so, we believe significant progress would be made on at least two fronts. First, retired athletes would be encouraged to acknowledge the power of generative acts in giving their new identity a greater sense of meaning. Second, athletes still participating in competitive sport would be prompted to consider retirement issues, engage in preretirement planning, and improve their own chances for a smooth career transition.

\section{References}

Allison, M.T., \& Meyer, C. (1988). Career problems and retirement among elite athletes: The female tennis professional. Sociology of Sport Journal, 5, 212-222.

Baillie, P.H.F., \& Danish, S.J. (1992). Understanding the career transition of athletes. The Sport Psychologist, 6, 77-98.

Baumeister, R. (1991). The meanings of life. New York: Guilford Press.

Bem, D. (1972). Self-perception theory. In L. Berkowitz (Ed.), Advances in experimental social psychology (Vol. 6; pp. 1-62). New York: Academic Press.

Billings, B.P. (1994). The importance of involvement in counseling. Journal of Reality Therapy, 13, 26-30.

Blinde, E., \& Stratta, T. (1992). The sport career death of college athletes: Involuntary and unanticipated sports exits. Journal of Sport Behavior, 15, 3-20.

Burke, D. (1990). Episode 14. In D. Burke (Producer), Burke's Backyard. Crows Nest, NSW: CTC Productions. 
Carver, C.S., Scheier, M.F., \& Weintraub, J.K. (1989). Assessing coping strategies: A theoretically based approach. Journal of Personality and Social Psychology, 56, 267-283.

Coakley, J.J. (1983). Leaving competitive sport: Retirement or rebirth? Quest, 35, 1-11.

Curtis, J., \& Ennis, R. (1988). Negative consequences of leaving competitive sport? Comparative findings for former elite-level hockey players. Sociology of Sport Journal, 5, 87-106.

Davis, M. (1993, August 7-8). Why a super athlete can turn problem child. The Weekend Australian, p. 22.

Erikson, E. (1963). Childhood and society (2nd ed.). New York: Norton.

Fitzsimons, P. (1990, October 26). Shane finds all that glitters is not gold. Sydney Morning Herald, p. 46.

Fong, M.L., \& Cox, B.G. (1989). Trust as an underlying dynamic in the counseling process: How clients test trust. In W. Dryden (Ed.), Key issues for counselling in action (pp. 26-36). London: Sage.

Gordon, H. (1994). Australia and the Olympic games. Brisbane: University of Queensland Press.

Gordon, S. (1995). Career transitions in competitive sport. In T. Morris \& J. Summers (Eds.), Sport psychology: Theory, applications and issues (pp. 474-501). Brisbane: Jacaranda Wiley.

Gould, S. (1972). Swimming the Shane Gould way. Sydney: Oak Tree Press.

Greendorfer, S.L., \& Blinde, E.M. (1985). "Retirement" from intercollegiate sport: Theoretical and empirical considerations. Sociology of Sport Journal, 2, 101-110.

Guilliatt, R., \& Dwyer, R. (1995, December 23). Personal best. Sydney Morning Herald, pp. 1-4.

Harvey, J.H. (1996). Embracing their memory: Loss and the social psychology of storytelling. Needham Heights, MA: Allyn \& Bacon.

Harvey, J.H., Orbuch, T. L., Chwalisz, K., \& Garwood, G. (1991). Coping with sexual assault: The roles of account-making and confiding. Journal of Traumatic Stress, 4 , 515-531.

Harvey, J.H., Orbuch, T. L., \& Weber, A. L. (1990). A social psychological model of account-making in response to severe stress. Journal of Language and Social Psychology, 9, 191-207.

Harvey, J.H., Orbuch, T. L., Weber, A. L., Merbach, N., \& Alt, R. (1992). House of pain and hope: Accounts of loss. Death Studies, 16, 99-124.

Harvey, J.H., Weber, A. L., \& Orbuch, T. L. (1990). Interpersonal accounts: A social psychological perspective. Oxford: Blackwell.

Hemery, D. (1986). The pursuit of sporting excellence: A study of sport's highest achievers. Champaign, IL: Human Kinetics.

Heatherton, T.F., \& Nichols, P.A. (1994). Personal accounts of successful versus failed attempts at life change. Personality and Social Psychology Bulletin, 20, 664-675.

Horowitz, M.J. (1986). Stress response syndromes (2nd ed.). Northvale, NJ: Jason Aronson.

Howell, R., \& Howell, M. (1988). Aussie gold: The story of Australia at the Olympics. Melbourne: Brooks Waterloo.

Innes, S. (1992, October). The pain of Shane not in vain. Sportsview, p. 6.

Jackson, S., Mayocchi, L., \& Dover, J. (1997). Life after gold II: Coping with change as an Olympic gold medalist. Manuscript submitted for publication.

Johns, D.P., Linder, K.J., \& Wolko, K. (1990). Understanding attrition in female competitive gymnastics: Applying social exchange theory. Sociology of Sport Journal, 7, 154-171. 
Kleiber, D.A., \& Brock, S.C. (1992). The effect of career-ending injuries on the subsequent well-being of elite college athletes. Sociology of Sport Journal, 9, 70-75.

Lavallee, D., Gordon, S., \& Grove, J.R. (1997). Retirement from sport and the loss of athletic identity. Journal of Personal and Interpersonal Loss, 2, 129-148.

Lazarus, R.S., \& Folkman, S. (1984). Stress, appraisal, and coping. New York: Springer.

Leick, N., \& Davidsen-Nielsen, M. (1991). Healing pain: Attachment, loss and grief therapy. New York: Tavistock/Routledge.

Lester, G. (1984). Australians at the Olympics: A definitive history. Sydney: Lester-Townsend. Lincoln, Y.S., \& Guba, E.G. (1985). Naturalistic inquiry. Newbury Park, CA: Sage.

McInnally, L.J., Cavin-Stice, J., \& Knoth, R.L. (1992). Adjustment following retirement from professional football. Paper presented at the annual meeting of the American Psychological Association, Washington D.C.

Meichenbaum, D., \& Fitzpatrick, D. (1993). A constructive narrative perspective on stress and coping: Stress inoculation applications. In L. Goldberger \& S. Breznitz (Eds.), Handbook of stress: Theoretical and clinical aspects (pp. 706-723). New York: Free Press.

Messner, M.A. (1992). Power at play: Sports and the problem of masculinity. Boston: Beacon Press.

Murphy, S.M. (1995). Transition in competitive sport: Maximizing individual potential. In S.M. Murphy (Ed.), Sport psychology interventions (pp. 331-346). Champaign, IL: Human Kinetics.

Ogilvie, B.C., \& Taylor, J. (1993). Career termination issues among elite athletes. In R. N. Singer, M. Murphey, \& L. K. Tennant (Eds.), Handbook of research on sport psychology (pp. 761-775). Sydney: Macmillan.

Parker, K.B. (1994). Has-beens and wanna-bes: Transition experiences of former major college football players. The Sport Psychologist, 8, 287-304.

Patton, M.Q. (1990). Qualitative evaluation and research methods. London: Sage.

Pennebaker, J.W. (1990). Opening up: The healing power of confiding in others. New York: Morrow.

Perna, F.M., Zaichkowsky, L., \& Bocknek, G. (1996). The association of mentoring with psychosocial development among male athletes at termination of college career. Journal of Applied Sport Psychology, 8, 76-88.

Petitpas, A., Champagne, D., Chartrand, J., Danish, S., \& Murphy, S. (1997). Athlete's guide to career planning. Champaign, IL: Human Kinetics.

Phillips, D.H. (1992). Australian women at the Olympic games 1912-92. Sydney: Kangaroo Press.

Riordan, R.J. (1996). Scriptotherapy: Therapeutic writing as a counseling adjunct. Journal of Counseling and Development, 74, 263-269.

Riordan, R J., \& Wilson, L. (1989). Bibliotherapy: Does it work? Journal of Counseling and Development, 67, 506-507.

Sinclair, D.A., \& Orlick, T. (1993). Positive transitions from high-performance sport. The Sport Psychologist, 7, 138-150.

Spera, S.P., Buhrfeind, E. D., \& Pennebaker, J. W. (1994). Expressive writing and coping with job loss. Academy of Management Journal, 37, 722-733.

Svoboda, B., \& Vanek, M. (1982). Retirement from high level competition. In T. Orlick, J.T. Partington, \& J.H. Salmela (Eds.), Proceedings of the 5th World Congress of Sport Psychology (pp. 166-175). Ottawa, ON: Coaching Association of Canada.

Swain, D.A. (1991). Withdrawal from sport and Schlossberg's model of transitions. Sociology of Sport Journal, 8, 152-160. 
Taylor, J., \& Ogilvie, B.C. (1994). A conceptual model of adaptation to retirement among athletes. Journal of Applied Sport Psychology, 6, 1-20.

Tricker, R., Cook, D.L., \& McGuire, R. (1989). Issues related to drug abuse in college athletics: Athletes at risk. The Sport Psychologist, 3, 155-165.

Weber, A.L., \& Harvey, J.H. (1994). Accounts in coping with relationship loss. In A. L. Weber \& J.H. Harvey (Eds.), Perspectives on close relationships (pp. 285-306). Needham Heights: Allyn \& Bacon.

Werthner, P., \& Orlick, T. (1986). Retirement experiences of successful Olympic athletes. International Journal of Sport Psychology, 17, 337-363.

Wolff, R., \& Lester, D. (1989). A theoretical basis for counseling the retired professional athlete. Psychological Reports, 64, 1043-1046.

Writer, L. (1990). Winning: Face to face with Australian sporting legends. Sydney: Ironbark Press.

Wylleman, P., De Knop, P., Menkehorst, H., Theeboom, M., \& Annerel, J. (1993). Career termination and social integration among elite athletes. In S. Serpa, J. Alves, V. Ferreira, \& A. Paula-Brito (Eds.), Proceedings: 8th World Congress of Sport Psychology (pp. 902-906). Lisbon: International Society of Sport Psychology.

\section{Acknowledgments}

The authors gratefully acknowledge the cooperation of Shane Gould Innes in the preparation of this manuscript. Correspondence concerning this article should be addressed to J. Robert Grove, Department of Human Movement, The University of Western Australia, Nedlands, 6907, Australia. Electronic mail may be sent via Internet to Bob.Grove @uwa.edu.au.

Manuscript submitted: January 15, 1997

Revision received: August 4, 1997 